\title{
Intermediality: Axis of Relevance
}

Rémy Besson, traduit par Caroline Bem

Over the past twenty years, the concept of intermediality has emerged as a strategic response that has sought to bypass some of the ills that have plagued the university as an institution. ${ }^{1}$ Indeed, defined as the study of "nodes of relations, of relationship movements slow enough to seem immobile," (Méchoulan) intermediality as an approach has helped the fight against the hyperspecialization of research in the humanities. By conceiving of relationships (as opposed to media forms also under investigation) as paramount, it has made it possible to view as counterintuitive a fragmented approach to the real and its representations. Thereby, the social and cultural environment has been relocated to the center of analyses pertaining to literature, film, theater, the visual arts, and digital productions. In such cases, intermediality is a tool that is placed in the service of a comparatist and multidisciplinary approach to research (Müller). As a concept, then, it is not thought as the property of specific objects, but as a shift in perspective on the part of scholars. $^{2}$

To the definition of the concept as a strategic response, we might add an aspect that is just as relevant, namely that of intermediality as an epistemological challenge. When it is deployed to pay special attention to technique and the materiality of forms in their relation to one another, intermediality constitutes a way of sidesteping intertextual or interdiscursive issues. ${ }^{3}$ The growing importance of the concept of intermediality takes the shape of a historiographical displacement that covers the entirety of the twentieth century. Within this trend, attention that was bestowed upon formats and other mediatic environments has come to be replaced, gradually, with a focus that rests on texts and, subsequently, on the relations between texts. ${ }^{4}$ Thus, equal amounts of attention are given to the content of analyzed artifacts - the production of meaning- 
and to the way in which this content acquires its form through its encounter with a specific format — the production of presence (Gumbrecht).

As an epistemological challenge and a strategic response, the success of the concept of intermediality can be accounted for, in equal measure, through favorable socio-cultural and technological conditions. Due to its contemporaneity with the development of the Web and the rise of social networks, intermediality has indeed benefited and contributed to the emergence of an environment that is conductive to a reflection on new technologies (Nouvelles Technologies de l'Information et de la Communication, to borrow an expression from the French communication sciences). Beyond this aspect, which is in part cyclical, the attractiveness of the concept lies in its intrinsically polysemous nature. The lack of consensus surrounding a definition of the term "medium" has been less an impediment than it has allowed for both complementary and distinct appropriations of the term to take hold. This article aims to put these different meanings into dialog with their consequences on the definition of intermediality. Indeed, a form of naturalization of the significance of "media," dependent upon its inscription within a given disciplinary field (semiology, literature, visual studies, communication sciences), is often observed. Going against this trend, I believe in the heuristic value of a polymorphic sense of the concept that does not, however, exclude more pointed questionings from being formulated at a later stage. The challenge here is to demonstrate the benefits of an awareness of the existence of these complementary approaches to the completion of a fully reflexive intermedial study. This requires, first and foremost, that the definition of the term "media" be itself revisited. Firstly, the term is sometimes used as a synonym for cultural productions or artworks. This type of approach is especially widespread amongst semiologists, art historians, and specialists of visual and literary studies. Within this framework, the transition from "intertextuality" to "intermediality" results, most commonly, from a desire to allot more space to the notion of technique. Secondly, it 
sometimes happens that a medium corresponds to a cultural series that has acquired a certain degree of autonomy vis-à-vis another, pre-existing medium. This is especially true in the fields of media archeology, the communication sciences, and cultural history. Thirdly, a medium is a necessary means toward the establishment of a relationship that is inscribed within a given milieu. Éric Méchoulan has written that "the medium is that which enables trade operations to take place within a certain community, both as a sense dispositif (stone, parchment, paper, and CRT screen that are media outlets) and as the milieu wherein exchanges take place" (19). This definition is more widespread amongst philosophers and those who are sensitive to sociological and anthropological issues.

I intend to create a correspondence between these three definitions and four fields of application for the concept of intermediality, which will be discussed over the remainder of this article. First, if a medium is a cultural production, the concept is used to think through the relations between the various mediatic formats that constitute the form under investigation. In this case, the adopted viewpoint is synchronic and co-presence becomes a key notion. Second, it is also possible to think about the relation to a given text as diachronical, either through the creation of a given medium (the genetic approach) or through its distribution (reception analysis). It is in this way that the notion of transference becomes central. Third, if one seeks to grasp what, at a certain point in time, distinguishes a medium from a cultural series, the notion of emergence seems most appropriate. Finally, if a medium corresponds to a set relationship within a given milieu, things get even more complex since it is now relations between cultural productions that, themselves, give rise to the links that must be analyzed as the constituents of a division of the sensible. ${ }^{5}$

In what follows, each of these key concepts - co-presence, transfer, emergence and milieu-is analyzed in turn, though this proposed subdivision is not intended to establish four stable definitions of the concept of intermediality. ${ }^{6}$ Indeed, it would be counterproductive to try to 
delimitate separate fields of investigation, since the strength of the concept lies in its ability to counteract compartmentalization; instead, my aim is to emphasize the existence of approaches that are both distinct and complementary. Finally, the article will conclude with a section that focuses on a case study of Massive Open Online Courses (MOOCs) to demonstrate the usefulness of apprehending a singular object from the four above-mentioned vantage points. As I will argue, such an approach leads, for instance, to a better understanding of the relevance, for scholars working within this field of inquiry, of a reflexive approach to the notion of intermediality.

\section{Co-presence}

To study intermediality at the level of a given cultural production is tantamount to falling back on the findings of intertextuality - namely that a form is always composed of other, pre-existing forms - and to stirring scholars' attention towards issues of technique. Thus, the existence of heterogeneous textual content is given less attention than are different media formats. Let us take as a case study a sequence from the documentary film Cheminots (Luc Joulé and Sébastien Jousse, 2009), which features an excerpt from the fiction film The Navigators (Ken Loach, 2001). The most obvious interpretation of this sequence, which takes place in a local trade union, centers on the political message conveyed by the film crew. Quite explicitly, the scene juxtaposes the rail sector situation in early twenty-first century France with a similar situation taking place in England during the Thatcher years. An intermedial approach focuses less on the reasons for including a clip from the Ken Loach film than it does on the way this clip is integrated into Joulé and Jousse's film. In that case, it is particularly worth noting that the fiction segment is videoprojected onto a mobile screen. The light thus produced by the projector at the center of the room facilitates the exchange of looks between unionists filmed in the documentary and those 
represented in the fiction. It is also worth noting that, although the film is distributed to railway workers with French subtitles, the soundtrack to Loach's film, as heard by the viewer of the documentary, is in French and not in English. In other words, sound editing can be assumed to have taken place, which raises a series of questions pertaining to the consequences of such a choice. ${ }^{7}$ Thus, it is the presence of a particular mediatic format within another that is studied here, mainly according to technical characteristics; a classic case of "intramediatic" citation or reference (a movie in a movie). The analysis of co-presence can also pertain to forms wherein a more or less high degree of heterogeneity is maintained. In such cases, the aim is to consider a hybridization process which, in some cases, results in an impossibility to assign content to a particular medium. The performance La Grande Guerre by the Dutch Theater Company Hotel Modern falls under this type of production. ${ }^{8}$ Indeed, during live performances of the piece, actors move around miniature characters within a décor that is reconstituted on stage. The actors also film the action that is then transmitted onto a screen in the background. Thus, spectators sitting in the audience are watching, simultaneously: 1) the miniature characters, 2) the actors who are moving them around, 3) the technical dispositif, and 4) the projection of the moving miniatures on a screen. There is a strong overlap here between theatrical set design and cinematographic (frontal projection indoors), or even televisual (live broadcast), format. Scholars who choose to focus on such issues of categorization from an intermedial standpoint examine co-present technical devices and the consequences of this co-presence on modes of representation (Larrue 13-29). This is an example of a larger phenomenon that is reflected, in particular, in the proliferation of neologisms associating several cultural forms (graphic novel, concert film, Web documentaries, etc.). This type of hybridization, sometimes associated with the phenomenon of convergence, gives rise to a perceived lack of distinction between media. In such a case, there would no longer be an interest in working on "inter-" forms, since all media would coalesce into 
a kind of global media environment. If such a historiographical trend exists at present, the concept of intermediality has the advantage of allowing us to think through that which resists this indifferentiation. The notion of mediativity, conceptualized by André Gaudreault and Philippe Marion as "a capacity to represent — and communicate the representation — that characterizes a given medium," (p. 48) is particularly useful in thinking through the persistence of a form of opacity within the relation that each medium entertains towards other media.

\section{Transfers}

A similar attention to that which resists that which connects-more so than it resists that which confuses - is equally present amongst researchers interested in apprehending the notion of transfer from an intermedial perspective. Thus, Silvestra Mariniello notes that "transfer, a nodal concept of contemporary culture, is understood here as the transport of materials or technologies from one culture to another, from one medium to another. The material and technology transferred are transformed in the process since their identity and meaning are based on the relationship to a context" (2011, p. 11). The main difference with the concept of co-presence is the fact that the perspective, here, is no longer synchronic but diachronic. In the cultural field, the canonical form of transfer is adaptation, which relies on the maintenance of a number of properties that make the first form always identifiable. For example, the Cannes Palme d'Or winner of 2013, La Vie d'Adèle by Abdellatif Kechiche, is an adaptation of a graphic novel by Julie Maroh, Le bleu est une couleur chaude (2010). Even more than the presence of a first embodiment in the second, it is through the terms of process, passage, and transformation, that the articulation between the two media forms is apprehended. In the case of the passage from graphic novel to film, what is typically examined is, for instance, the connection between the framework of the cartoon boxes and the framing of the camera operator, or between the pencil 
lines and the contours of the faces filmed. The issues will then have less to do with authenticity, or with the liberties taken by the one doing the adapting, than they will take as their object the thus newly-proposed mediatic dispositifs. In this way, intermediality takes up the Deleuzian notion that "having an idea in [something]" is to denote the fact that an identical story will not give rise to narrative in the same way, regardless of whether it is adapted to the cinema, the theater, or a commercial segment.

In addition to the concept of adaptation, the notion of transfer allows us to understand the migration phenomena of reuse and recycling, which are limited to a segment (sometimes unrecognizable) within a first production. In this case, as in the first, the attention of scholars is focused on the temporality of the production of forms. It thus adopts a so-called genetic approach. If this state of affairs has been accepted thus far, it is worth noting that an analysis in terms of transfer can also relate to the time of distribution of cultural productions within public space. In that case, the focus rests on an analysis of the circulations of forms. Here, the key concept, also mobilized in the fields of the digital humanities and visual culture, is that of appropriation (or appropriability). The question of reception, then, becomes central: if the receiver has, thus far, been assimilated to the figure of the spectator of a performance taking place before his or her eyes, it is now possible to consider the receiver as an active user of a mediatic process that does not exist beyond him or herself. The creation, by fans, of parodic videos or of homages to television series (Jenkins) and the posting of such content onto social networks, gives rise to a field of practices that can be studied: as much, if not more, than the distribution of contents, amateur gestures make visible how media are, at once, the objects upon which conversations between peers come to bear and the sites wherein these conversations evolve. 


\section{Emergence}

If, at the end of the previous section, the role occupied by users within mediatic dispositifs was central to the investigation, the notion of emergence, in turn, demands that we pay attention to the medium as such. As cinema and literature theorist Rick Altman puts it, "intermediality should designate, in my opinion, an historic step, a transient state in which a form developing into a fullfledged medium is still divided into several existing media to such an extent that its own identity remains in suspension." Such an approach relies on a clear distinction between the moment when a technological innovation is developed and that when it becomes a medium in its own right. The study of emergence, then, focuses on a socio-cultural process of institutionalization. Thus, André Gaudreault notes, in Cinéma et Attraction, that "what we are clearly referring to, even if only implicitly, is the institution that the cinema became, with its rules, constraints, exclusions and procedures" $(67)^{10}$. As he makes clear, this transition corresponds to the cinema's process of individuation from the performing arts that took place over a period of more than twenty years (1890-1915). The birth of cinema does not correspond to the invention of a special technical device, but to the recognition, by a set of social actors, of the existence of a specific social form. This requires the taking into account of data that are no longer primarily formal but also economic, legal, political and cultural. Philippe Despoix writes that "it appears crucial not to separate the existence of the technical apparatus from that of political, scientific or artistic configurations but, rather, to understand them within their fundamental interrelationships." (p. 43). For instance, the becoming medium of a cultural series can, amongst other processes, be linked to the creation of a corporate press or to the emergence of institutions of control at a national or international level. The discourse whereby inventors and/or industrials justify the existence of a medium and the appropriations to which it becomes subjected are of particular relevance when it comes to understanding such phenomena. ${ }^{11}$ Such an interpretation also makes 
clear why, in spite of a series of technical changes (digital projection, the ever-growing number of individual screens, etc.), the term "cinema" remains relevant in the early twenty-first century (Gaudreault, 2013). Indeed, it is not the change of a technological variable-a specific type of projection device, for instance - that leads to a radical questioning of the medium; rather, the medium is understood as a protean social body.

In order to fully grasp the concept of emergence, it is also important to understand that the institutionalization of a medium is most often interpreted as its individuation from another medium (Bolter and Grusin). To this between media —one whose form is no longer fully present and the other which is not yet constituted - Gaudreault proposes to apply the term cultural series. Most often, this term is used in the plural form to mirror the way in which a medium constitutes itself at the intersection of several concurrent processes of individuation. Taking the case of the cinema, for instance, it is seen to emerge from the collision of photography, chronophotography, light projection, and magic lantern shows, amongst others. The notion of intermediality, then, is particularly useful in that it maintains, for as long as possible, the taking into account of a certain degree of heterogeneity among the elements that make up a medium still caught in a process of becoming. This, in turn, makes it possible to avoid adopting an anachronistic and teleological standpoint or, in other words, to avoid taking for granted that the emergence of a medium is selfevident and that a medium is an entity with fixed and natural properties. In this way, intermedial thinking is anti-essentialist: it promotes the study of dynamics, the ephemeral, the evanescent, or even that which has not yet occurred. Indeed, the notion of cultural series makes it possible to apprehend cultural forms as media that had, previously, not been recognized as such; simultaneously, it also suggests that a specific type of production that was, at one time, considered a medium can subsequently lose its status. ${ }^{12}$ In addition, the study of emergence pays equal attention to that which both precedes and follows the becoming medium of a cultural series. 
Thus, if most specialists begin their study of a medium from the moment it is recognized as such, an intermedial approach also pays attention to what happens prior to the completion of that process, with scholars invested in such an approach focusing their analyses on phenomena that have a tendency, otherwise, to go unnoticed. From this vantage point, intermediality is closer to media archaeology than it is to media history (Parikka). To summarize, then, the purpose is not, within this third perspective, to identify relations between two creators or several forms of cultural production in particular (as is the case with co-presence or transfer); instead, it is to observe how cultural series give rise to a specific medium at a particular point in time.

\section{The Environment}

By focusing on the notion of the environment, or milieu, this last section aims at placing the user back into the centre of the mediatic dispositif. Nonetheless, to the extent that the user is no longer considered to be the one who manipulates a medium exterior to him or her, but rather views it as one constituent within a larger mediatic environment, this approach is distinct from that of the transfer. Silvestra Mariniello thus explains that "[intermediality] marks the passage from a theory of society that contains media - a widely established conception nowadays - to a theory where society, sociality and media are understood to constantly build and destroy one another" (2011 13). Consequently, no interaction can be viewed as non-mediated; in other words, where communication is present, there is also necessarily a medium. In turn, this medium can be seen to acquire a political dimension to the extent that it participates in the organization of the life of the city: it is the medium that makes possible the unfolding of shared experience. It is not that which represents politics (as is the case, for instance, in the film Les Cheminots), but it becomes the milieu where the political occurs.

An intermedial approach, then, consists in taking into consideration space-time complexes 
wherein individuals united as groups move about. It is understood that these groups make use of singular sense inscriptions (a letter, a book, a text message, a film, a comic, a Website) that take the shape within specific mediatic formats (stone, paper, screen) and are indissociable from a given milieu (a given society whose norms are the product of a specific historical moment) that is at once cultural, social, political, economical and technological. The situation under consideration is complex, since the purpose is to study the different ways in which relations develop between standardized forms that (already) give rise to relations between individuals. In addition, the point is not to put into communication potentially separate elements, but rather to apprehend constructs, or complex systems of relations, which, taken together, are constitutive of an intermedia-whole. In this case, the prefix "inter-" speaks to the act of studying that which occurs between the three distinct aspects of a medium: sense inscription, media format and milieu. Here, then, the aim is to establish links between these three nodes by bringing them closer together and, simultaneously, by measuring the distances between them. Moreover, it is necessary to consider what takes place at the points that connect different media; this is done either node by node or transversally. Thus, the question of the institution, which regulates and sanctions, can be seen to resurface, once again, within the discussion of emergence. As Éric Méchoulan asks of his reader: "who masters the techniques, who authorizes the effects, who ensures that distribution should be as important as the author of this or that work, if one considers that meanings do not pass from one brain to another in an immaterial and immediate way as they do in angelic communication?" (17).

This Foucauldian approach to the institution is equally relevant to a theory of dispositifs as it applies to artistic products, while the notion of milieu is similarly adapted to the study of singular cultural production. ${ }^{13}$ The purpose, then, is to connect the first and last section of this text (i.e. copresence and milieu) by way of an ultimate notional displacement. Silvestra Mariniello, for 
instance, has analyzed Paolo and Vittorio Taviani's documentary Cesare deve morire (2012) by drawing, rather than on the mere observation of technological film formats, on the aforementioned concepts of sense inscriptions, the environment, and media formats. ${ }^{14}$ In this film, the inmates of a prison in Rome rehearse a Shakespearean text that intersects with their personal experiences and, ultimately, transforms them. The point, here, is to make visible what takes place during the production and to capture the unfolding of human relations within a given public space. Film form, in this case, is no longer considered autonomously (as a space of presence) but becomes inscribed within public space where it is seen to bear a transformative effect upon both the group that participates in the Shakespearean production and the film viewing audience itself.

\section{MOOCs: A Case Study}

Before concluding this article, I want to test out the aforementioned approaches by applying them to a concrete object. My case study takes as its object Massive Open Online Courses (MOOC), a method of education that came into fashion in 2012 - for instance through the rise of platforms such as Udacity, Coursera and $E d x$ - before coming under attack in $2013 .{ }^{15}$ Initially enthusiastic responses soon gave way to more reflexive approaches (Mangenot) that combine MOOC pioneers' educational and humanist ambitions (mainly connectivist and sometimes tinged with progressivism and technophilia) with increasingly overt attempts to promote sponsor brands and economies of scale (lowering the cost of education per student) (Holland and Tirthali). If the coexistence of these different objectives creates a blur around its definitional criteria (Moeglin), this format is, at the very least, characterized by free education (after registration) and its ability to cater to substantial cohorts of students (for a synthetis, read Karsentin). As complex objects 
that combine institutional, economic, legal, educational and technical aspects, MOOCs are especially well suited to an intermedial approach.

The study of co-presence constitutes a relevant point of entry into an analysis of the different media formats that constitute MOOCs (audiovisual clips, older animated sequences, diagrams and other still images, as well as texts). Such an approach leads to an interrogation of the hierarchical (amongst others) ties between the various constituents of this form. Marc Henri Piault's course, "Anthropologie et Cinéma," for instance, clearly positions audiovisual content at the heart of mediation. Facing the camera, the lecturer's body is shown in alternation with a series of clips taken from the film he is discussing. Additional materials, such as the written summary of the course, associated documents, a bibliography, and a filmography, as well as a list of links, clearly complement the filmed course as it is made available online. The relationship between audiovisual data and written data about that data (metadata) is, in other words, of central importance here. Unlike this example, the course Anthropologie visuelle et techniques du corps creates a back-and-forth between a text that incorporates numerous hyperlinks (referrals to other sites or to an index and a bibliography) and a sequence that integrates filmed extracts. In this case, the hierarchy between different media formats presents itself differently, namely because it allows Internet users to rely exclusively on written content for the duration of the course. The relationship between text and paratext, written and oral, sound and visual varies depending on ergonomic choices that do or do not affect the adopted pedagogical model. ${ }^{16}$ Beyond these rather strictly semiotic remarks, the notion of co-presence also allows for a thinking through of the ways in which user-generated data that are produced during the course can be managed effectively. Indeed, such data oftentimes give rise to other offerings (similar courses, advertising, etc.) or to changes in content (ad personam programs etc.). To the question of the modulatory quality of MOOCs, we might now add a further issue: the ethical and legal questions that concern the 
protection of students. Data are being archived, reused, and sometimes re-sold; they stand, in any case, at the heart of the economic model of MOOCs, a model that is still in the process of being defined. Here, it is necessary to remember that this approach leads to the so-called discreet apprehension of elements that are not visible while surfing a MOOC's interface. This type of undertaking, then, leads to the realization that MOOCs are not, oftentimes, solely limited to a specifically dedicated platform, such as Coursera for instance; rather, they unfold across a variety of formats such as social networks in particular. In 2013, for instance, Internet users registered in E-Learning and Digital culture, a course offered by the University of Edinburgh, created a digital artefact that they were then invited to share online in order to facilitate group discussion. ${ }^{17}$ In addition to ethical and legal dimensions, then, it is equally necessary to consider an economic and institutional logic_-who owns the thusly created content?, for instance - in order to understand these media constructs.

The notion of transfer serves primarily to make graspable what is at stake when a course that was first given in person is adapted to a Web format. ${ }^{18}$ Examples range from filmed conferences that are then uploaded online to the creation of dedicated interfaces leading to an almost complete reconfiguration of modes of knowledge sharing. ${ }^{19}$ In the first case, the guiding principle is that of transparency, since the Web is apprehended in the manner of a channel that presents in the most neutral way possible a lesson taught in person (McConachie and Schmidt); in the other case, a form of hypermediality is at work (the medium is seen to reveal itself), which poses the question of the extent to which the Web's mediativity is taken into account. Multiple intermediary formats exist whereby extracts of classes taught in person are sometimes re-edited or replayed as part of online course offerings. What is more, an approach in terms of transfer allows, in turn, for a thinking through of the ways in which the Web alters in person practices. To study MOOCs, in other words, means to observe the evolution of university courses at large. The two types of 
education lead to reciprocal forms of adaptation through a constant balancing movement between mediation, via new technical formats, and the remediation of previous formats. MOOCs, for instance, can in certain instances be considered as "tutored," which means that all knowledge is made available online while in person exchanges are occurring within the physical space of the university (flipped classroom) (Epelboin, Pomerol and Thoury). This model, however, is not compatible with the idea of bringing together cohorts of several thousands of learners and achieving substantial economies of scale (Depover). In such cases, MOOCs turn into SPOCs (Small Private Online Courses), which leads to a rethinking of the relationship between "in person" and "Web" teaching in terms other than competition or of a substitution of one mode by the other. Consequently, the process of institutionalization can be analyzed and understood as a transfer from "Web" to "in person" teaching or, in other words, to a reincorporation of the Web's finality within the walls of the university.

The use of the concept of emergence, in turn, is linked to a change of scale: its purpose is to interrogate the phenomenon of MOOCs by connecting the cultural and technological dimensions of the great digital conversion. ${ }^{20}$ Diachronically, it is then possible to reinscribe the emergence of MOOCs within the relatively long time of long distance learning (the sending out of typescripts, then audio tapes, VHS and DVD) and the comparatively shorter circulation time of free online learning tools. Such a move makes it possible to better perceive consistencies and changes within these practices, as well as within the discourses - at first overwhelmingly utopian (2011-2012), then dystopian (2013) — surrounding this emerging course format. From what can be called, this time, a synchronic point of view, MOOCs can be compared to other cultural series related to the advent of the digital age, such as interactive documentary films, dynamic cartographies, virtual exhibitions, or also documentary Websites. This approach rests on the idea that the form and issues of a particular MOOC may well be closer to the cultural production of another mediatic 
format than they might be to another online course. In order to be truly heuristic, such comparisons suggest that a questioning of categorization necessarily implies a consideration of educational intent, institutional constraints, technological standards, and economic and legal aspects. If the above-mentioned elements (law, economics, institution, pedagogy) have thus far been used to better understand a singular arrangement, a type of transfer, or a moment of emergence that is, first and foremost, of a mediatic nature (technical and cultural), the latter become, in cases where media are considered as milieux, themselves objects of investigation. Now, the topic under investigation is no longer the online course considered within a protean context whose nature it seeks to participate in defining; instead, the MOOC is now construed as a sufficiently circumscribed avenue of entry that makes graspable what is being played out within a complex environment at a given point in time. Consequently, the importance of the technical dimension, which seemed so central to discussions of co-presence, transfer or emergence, finds itself relativized. Indeed, the digitally-induced evolution that has shaken the field of education since 2011 can be considered cultural as much as technological (Rieffel). Intermediality, then, offers a way to reflect on the current state of the university as institution by questioning, for instance, its hackneyed conservatisms, effects of opportunity, underlying economic logics, and the specific rapport it entertains with temporality. At the level of the individual, in turn, an intermedial approach poses the question of the reconfiguration of relations between technicians, administrative and teaching bodies, and students. ${ }^{21}$ Indeed, "MOOCs are not only building new relationships between students and educators, but also between different roles and departments at universities." (White, Leon and White). Thus, it is important to scrutinize the change in spaces of play, which allowed for creative crafting activities that resulted from the implementation of innovation (2008-2011) and managerial practices, in terms of a rationalizing of this same innovation (2012) through education resource allocations. The notion of milieu thus leads to a 
reflection on the implications — and sometimes on the lack of societal involvement — that derive from the development of online courses, both for those who design them and for those who use them as part of their training. In other words, it inquires into how the modalities of a division of the sensible come to be reconfigured (or not) during, first, the emergence, and then the institutionalization, of a new media format. The presentation of these complementary areas of investigation that the notion of intermediality covers does not offer an overarching response to the question of online courses; in order to achieve this, a more restrained corpus and a more precise research question would need to be determined. Instead, this article has highlighted the plurality of the in-between media that confronts scholars of this area leading, in turn, to a denaturalization of the — at first sight relatively simple — definition of the term "medium," as well as to a multiplication of the possible meanings of "intermediality."

\section{Conclusion}

To conclude this attempted categorization, then, it remains necessary to emphasize the resolutely polysemic character of the notion of intermediality, which renders graspable phenomena of copresence within a singular cultural production, as well as transfers from one form to another, the emergence of a new medium, or lived experience within a given milieu. Conceived primarily as a strategic response, the concept has thus given rise, over the past fifteen years, to an epistemological challenge, which has led numerous scholars to consider much-studied objects in a new light. To present this research, the four parts of this article have been conceived to entertain a complementary, but also progressively complex, relationship with one another. Indeed, the notion of co-presence refers to operations relatively similar to those of intertextuality and interdiscursivity, where the notion of milieu leads to an abandonment of the very idea of medium (the most commonly used term in such writings is that of "media environment"). This marks a transition from a relatively restrictive view, close to a semiotics that integrates a reflection on 
technology, to a broader significance that incorporates questionings ranging from the political to issues of society and history. However, it would be wrong to read these four parts in terms of a historiographical progression or as a replacement of one way of thinking by another. Rather, these four parts should be taken as nodes - co-presence, transfer, emergence, and milieu — that are most fruitfully deployed, one after another, within the context of an intermedial study. This, precisely, is what the fifth part, that takes MOOCs as an object of study, has aimed to demonstrate. Indeed, if certain researchers inscribe their work within this or that particular pattern, it is often only for a time, and in any case, their objects of study can be considered in the light of the other three axes. To conclude, then, we might note that the heuristic value of a nonlinear path between the four above-mentioned polarities and the counterproductive nature of overly rigid definitions has allowed intermediality to not become a discipline. Instead, as media theorist Jürgen E. Müller has suggested, intermediality is an axis of historical relevance. From this perspective, it always articulates itself through practices borrowed from other disciplinesanthropology, literary studies, film and theater, history, philosophy, sociology-whose theoretical assumptions it questions and whose unspoken institutional tenets (e.g. hyper specialisation, a rejection of comparativism and of transversal approaches) it seeks to subvert. Thus, intermediality constitutes a limited approach for those looking for methodological solutions, as much as it offers a valuable resource for those seeking to question their own research practice.

Postdoctoral fellow at LLA-CREATIS (Toulouse 2), associated researcher at CRIalt (Université de Montréal). 


\section{Cited cultural productions:}

Kechiche, Abdellatif, dir. La Vie d'Adèle, 2013, Fiction movie, Colors, French, 187 min.

Maroh, Julie, Le bleu est une couleur chaude, 2010, Comic, French, 160 p.

Taviani, Paolo and Vittorio Taviani, dir. César doit mourir, 2012, Documentary, Colors, Italian, $76 \mathrm{~min}$.

Sauer, Arthur and the Company Hotel Modern, dir. La Grande Guerre, 2001, Dutch, 70 min.

Loach, Ken, dir. The Navigators, 2001, Fiction movie, Colors, English, 96 min.

Joulé, Luc and Sébastien Jousse, dir. Cheminots, 2009, Documentary, Colors, French, 81 min.

Comolli, Annie and al., Anthropologie visuelle et techniques du corps, Université de Nice Sophia Antipolis, 2012 [Online].

Piault, Marc Henri. “Anthropologie et Cinéma.” University Aix-Marseille (TéléAMU), 2013

[Online].

Works Cited

Albera, François, Alain Boillat, Alain Carou, and Laurent Le Forestier. "Pour une nouvelle histoire du cinématographe : Cinq questions à André Gaudreault." 1895. Mille huit cent quatrevingt-quinze 57 (2009): 9-16.

Albera, François, and Maria Tortajada (dir.). Ciné-dispositifs: spectacles, cinéma, télévision, littérature. Lausanne : L'Âge d'homme, 2011.

Besson, Rémy. "Face à face entre Cheminots (2009) et Navigators (2001)." Cinémadoc, 22 July 2012. Web. 15 April 2015.

_. "MOOC et méta-MOOC sont sur le réseau..." Cinémadoc, 7 March 2013. Web. 15 April 2015.

Bolter, Jay David and Richard Grusin. Remediation, Understanding New Media. Boston: MIT Press, 1999.

Boullier, Dominique. "MOOC : en attendant l'innovation." Distances et médiations des savoirs 6 (2014). Web. 15 April 2015.

Depover, Christian. "Quels modèles économiques et pédagogiques pour les MOOC ?" Distances et médiations des savoirs 5, 2014. Web. 15 April 2015.

Despoix, Phillipe. Interview with Sylvano Santinia. "Intermédium et porosité disciplinaire:

parcours intermédial de Philippe Despoix." Spirale: arts, lettres, sciences humaines 233 (2010) : 41-44.

Doueihi, Milad. La Grande conversion numérique. Seuil : Paris, 2008 
Epelboin, Yves, Jean-Charles Pomerol, and Claire Thoury. Les MOOC. Conception, usage et modèles économiques. Paris: Dunot, 2014.

Foucault, Michel. "Le jeu." Dits et Écrits, tome 3 : 1976-1979. Paris : Gallimard, 1994.

Gaudreault, André. Cinéma et attraction, Pour une nouvelle histoire du cinématographe. Paris :

CNRS Éditions, 2007.

_. La fin du cinéma? Paris : Armand Colin, 2013.

Gaudreault, André, and Philippe Marion. "Transécriture et médiatique narrative. L'enjeu de

l'intermédialité." La Transécriture. Pour une théorie de l'adaptation. Ed. André Gaudreault and

Thierry Groensteen. Québec/Angoulême : Nota Bene/Centre national de la bande dessinée et de l'image, 1998.

Gumbrecht, Hans Ulrich. “Why Intermediality - if at all?” Intermédialités 2 (2003) : 173-178.

Hollands, Fiona M. and Devayani Tirthali. MOOCs: expectations and reality. Full report. New York : Columbia University (2014). Web. 15 April 2015.

Jenkins, Henry. Fans, Bloggers, and Gamers: Exploring Participatory Culture. New York: New York University Press, 2006.

Karsentin, Thierry. "MOOC. Révolution ou simple effet de mode?" Revue internationale des technologies en pédagogie universitaire 10.2 (2013): 6-22.

Larrue, Jean-Marc. "Théâtre et intermédialité. Une rencontre tardive.”Intermédialités 12 (2008) : 13-29.

Mangenot, François. "MOOC : hypothèses sur l'engouement pour un objet mal identifié."

Distances et médiations des savoirs 7 (2014). Web. 15 April 2015.

Marinello, Silvestra. "L'intermédialité : un concept polymorphe" Inter Média. Ed. Isabel Rio Novo and Célia Vieira. Paris : L'Harmattan, $2011: 11-30$.

Méchoulan, Éric. "Intermédialités : le temps des illusions perdues." Intermédialités 1 (2003) : 927.

McConachie, Katherine and Philipp Schmidt. "Why there are so many video lectures in online learning, and why there probably shouldn't be." Medium, 17 June 2015. Web. 25 June 2015.

Moeglin, Pierre. "L'enseignement supérieur au défi du numérique. MOOC : de l'importance d'un épiphénomène." Futuribles 398 (2014): 5-21.

Müller, Jurgen E. "L'intermédialité, une nouvelle approche interdisciplinaire : perspectives théoriques et pratiques à l'exemple de la vision de la télévision", Cinémas : revue d'études cinématographiques 10. 2-3 (2000) : 105-134.

Parikka, Jussi. What is Media Archaeology? Cambridge: Polity Press, 2012.

Rancière, Jacques. Le Partage du sensible, esthétique et politique. Paris : La Fabrique, 2000.

Rieffel, Rémy. Révolution numérique, révolution culturelle? Paris : Gallimard, 2014.

White, Steve, Manuel Leon and Sue White. "MOOCs Inside Universities." Proceedings of the

7th International Conference on Computer Supported Education, Lisbon (2015): 109-115.

\footnotetext{
${ }^{1}$ I borrow this term from Foucault on the concept of the "devise."

${ }^{2}$ This last point has been debated extensively within the scientific community since some researchers have attempted to define intermedial properties as specific to particular forms. Typically, in France, the term "intermediality" is used
} 
to describe the object that is being studied; in such cases, however, I prefer to use the term "multimedia" or "plurimedia."

${ }^{3}$ In short, and certainly too quickly, "intertextuality" means to think the text (which can be a film, site, etc.), as the place where the presence of other texts is made manifest. This may include explicit references, in the form of appropriations or citations, as well as elements that go beyond the intentionality of the one who designed the text. It is possible to distinguish the notion of "interdiscursivity" from that of "intertextuality," since the former focuses more on the inclusion of the text in its social, cultural and temporal context in time, and on modes of production as well as distribution.

${ }^{4}$ In this regard, the emergence of the term "intermediality" refers to the study of relationships between materials that are compounds of analyzed cultural productions. I refer here to research led by Thomas Strassle at the Haute École des arts of Berne.

${ }^{5}$ I refer to Rancière.

${ }^{6}$ This is to match the text to this incompleteness, which promotes subsequent exposure of problematic situations, fixing theoretical definitions.

${ }^{7}$ For a deeper analysis, refer to Besson, July 22, 2012.

8 For a more detailed presentation, see the Company's Website, URL : http://www.hotelmodern.nl/flash_en/lobby/lobby.html, accessed April 15, 2015.

${ }^{9}$ On that topic, it is possible to see the famous lecture of the philosopher at la Fémis (May 15, 1987), bonus material in the DVD edition by Pierre-André Boutang and Michel Pamart, L'abécédaire de Gille Deleuze, Paris, Éditions Montparnasse.

10. The theses of this book did not go without generating a debate among specialists of early cinema, see François Albera, Alain Boillat, Alain Carou and Laurent Le Forestier.

${ }^{11}$ Discourse analysis is as important as the technic (Albera and Tortajada).

${ }^{12}$ Beyond the study of the emergence of a medium, the concept of cultural series is particularly relevant for intermedial studies, since it allows to conceive that there are sometimes more gains in bringing together cultural series (or productions integrating into separate series) than to reunite the units (in this case, the film) of the same series (they often are very different economically, legally, formally, politically, etc.).

${ }^{13}$ For more details on this subject, read the article by Monique Martinez featured in this issue.

${ }^{14}$ Lecture given on April 8, 2014 in the international Seminary "Archiver le geste créateur »,

Departement of Theatral studies of the Université Rennes 2 - CRIalt (Université de Montréal).

${ }^{15}$ Read, for example, Le Débat 180, 2014.

${ }^{16}$ Boullier insists on the fact that online transition is not always accompanied by a pedagogical reflection.

${ }^{17}$ The design of these objects was not only a sideline, but a medium of exchange between learners leading to the emergence of new knowledge and new expertise. For more on this topic, read Besson, 2013.

${ }^{18}$ The transfer can also occur from a book to an online course, as it is the case with Piault.

${ }^{19}$ It is here possible to think about formats closed to serious games.

${ }^{20}$ This is taken explicitly from the title of the book by Doueihi.

${ }^{21}$ This raises the question, in particular, of the links between media professionals and education sciences. 